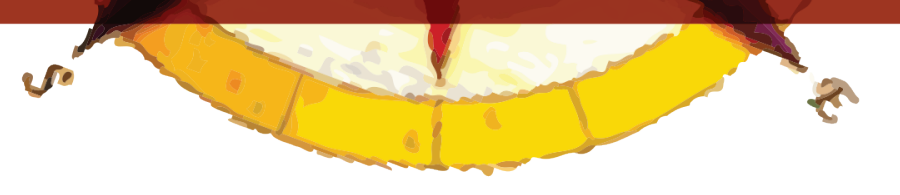

\title{
ESTRATÉGIAS DE ENSINO E MOBILIZAÇÃO DOS CONTEÚDOS DO CLIMA NA GEOGRAFIA ESCOLAR: POSSIBILIDADES DE AÇÃO DIDÁTICA POR MEIO DE MATERIAIS DIDÁTICOS
}

\author{
Adriana Olivia Alves ${ }^{1}$
}

\section{RESUMO}

Este texto discute alguns pressupostos teórico-metodológicos das estratégias de ensino, o ensino dos conteúdos do clima na Geografia Escolar e a trajetória de elaboração de um material didático - fascículo. Parte-se da discussão das estratégias enquanto possibilidade de mobilização de conteúdos teórico-práticos (saber-fazer) com vistas a mobilização dos conteúdos do clima na Geografia Escolar.

Como o objetivo de suprir demandas de ensino e aprendizagem de temas recorrentes no trabalho docente e no cotidiano escolar na Região Metropolitana de Goiânia (RMG). Estas questões, bem como a realização desta pesquisa surgiram em decorrência do desenvolvimento de trabalho conjunto de professores da Rede de Ensino Pública Estadual de Goiás, Municipal de Goiânia, alunos de graduação e pós-graduação e professores do ensino superior que lecionam conteúdos pedagógicos e específicos em Geografia.

\footnotetext{
Palavras - chaves: Estratégias de ensino - conteúdos do clima - elaboração de materiais didáti$\cos$
}

\begin{abstract}
This paper discusses some theoretical and methodological assumptions of teaching strategies, teaching the content in Geography School climate and the trajectory of development of educational material - issue. It starts with the discussion of possible strategies while raising theoretical and practical contents (know-how) in order to mobilize the contents climate in Geography School. Since the goal of supplying the demands of teaching and learning of recurring themes in teaching and in school life in the Metropolitan Region of Goiânia (RMG). These issues, as well as this research emerged due to the development of joint work of teachers of the State Public Education of Goiás, Goiânia City, graduate and post-graduate students and university teachers who teach educational content and specific Geography.
\end{abstract}


Key words: Teaching strategies - contents climate - development of teaching materials

\section{RESUMEN}

En este trabajo se analizan algunos supuestos teóricos y metodológicos de las estrategias de enseñanza, así como de los contenidos en el clima escolar Geografía y la trayectoria de desarrollo de material educativo - tema. Se inicia con la discusión de las posibles estrategias mientras levanta contenidos teóricos y prácticos (know-how) con el fin de movilizar el clima contenidos en la Escuela de Geografía. Dado que el objetivo de abastecer las demandas de la enseñanza y el aprendizaje de los temas recurrentes en la enseñanza y en la vida escolar en la Región Metropolitana de Goiânia (RMG). Estas cuestiones, así como la investigación surgió debido al desarrollo del trabajo conjunto de los profesores de la Educación Pública del Estado de Goiás, Goiânia Ciudad, los estudiantes de grado y postgrado y profesores universitarios que imparten contenidos educativos y específicos Geografía.

Palabras clave: Estrategias de enseñanza - Contenido climático - desarrollo de materiales didácticos

\section{INTRODUÇÃO}

Enquanto pesquisadora, o contexto da abordagem do tema está relacionada de um lado, a trajetória de investigações vinculadas ao Ensino de Geografia Física e, do outro, às práticas docentes correlatas às disciplinas de domínio da área de Didática em Geografia e Estágio Supervisionado.

Ao mesmo tempo, por estar instalada profissionalmente no Laboratório de Estudos e Pesquisas em Educação Geográfica - LEPEG, junto à Universidade Federal de Goiás - UFG, encontramos ambiente propício para o desenvolvimento de pesquisa em apreço, em virtude da trajetória de investigações e metodologias na elaboração de materiais didáticos na forma de fascículos didáticos junto à Região Metropolitana de Goiânia - RMG, que contribui para a efetivação da formação do professor de Geografia numa perspectiva mais acadêmica.

Essa propensão decorre da constituição de uma Rede de Pesquisa em Ensino de Cidade -REPEC. Constituída em 2007, esse grupo de pesquisa tem realizado vários trabalhos: quatro fascículos sobre a RMG (um sobre a cartografia, outro sobre bacia hidrográfica, um sobre o urbano, outro a violência urbana, dinâmica populacional e dinâmica econômica). Outro aspecto importante dessa rede foi a estreita vinculação com os professores das escolas na efetivação desse trabalho. A efetiva participação no desenvolvimento de pesquisa sobre o ensino da Geografia está associada à concepção de Demo (2005) no que diz respeito ao ato de educar pela pesquisa.

\section{PRESSUPOSTOS TEÓRICO-METODOLÓGICOS DAS ESTRATÉGIAS DE ENSINO}

A temática das estratégias de ensino desempenha papel fundamental no processo de formação inicial e continuada de professores. Assim como a organização e sistematização dos conteúdos teórico e conceituais. Partimos do pressuposto que as estratégias de ensino ou procedimentos metodológicos 
façam parte do planejamento escolar de todo professor. Ao mesmo tempo, podem ser consideradas ótimos instrumentos para verificação de aprendizagem, tanto de conteúdos específicos, como as habilidades desenvolvidas, indispensável para a avaliação formativa.

O termo estratégias de ensino são designadas de forma diferenciada conforme a bibliografia disponível. Por exemplo, Savianni (1985) e Rangel (2005), diferenciam como métodos de ensino; Luckesi (1991) e Cavalcanti (2012) apontam como procedimentos de ensino; (Luckesi, 1991); Veiga (1993 e 2006) apresenta como técnicas de ensino; Vianin (2013) e Farias et al. (2009), assinalam como estratégias de ensino, Masseto define como técnicas de ensino; enquanto que Anastasicou e Alves (2004) caracterizam o termo estratégias de ensinagem, que aglutina o processo de ensino e aprendizagem.

Concordamos com Anastasiou e Alves (2004), ao afirmar que as estratégias referem-se à "[...] a arte de aplicar ou explorar os meios e condições favoráveis ou disponíveis, com vistas a consecução dos objetivos." Nesta perspectiva, não tem como deixar de admitir que a aprendizagem das estratégias de ensino, mobilizam o conteúdo procedimental, que "[...] inclui entre os outras coisas as regras, as técnicas, os procedimentos - é um conjunto de ações ordenadas e com um fim, quer dizer, dirigidas para a realização de um objetivo."(Zabala, 1998, p.43)

A aprendizagem é o ponto central da ação docente, onde os objetivos irão permitir o desenvolvimento dos aprendizes na mobilização a aquisição de conhecimentos. No entanto, na realização do trabalho docente alguns erros de interpretação das estratégias de ensino são comumente empregados devido o caráter inicialmente, técnico e procedimental utilizados durante a ação didática. Dentre os mais comuns podemos destacar:

1. Fazeção: Considerar as estratégias como fazeção, ou seja, atividade de realização de cunho estritamente manual, que pressupõe a mobilização de conteúdos procedimentais, sem contudo, haver um processo elaborativo de construção teórica, ou seja, um saber-fazer destituído de um sentido conceitual.

2. Receita de bolo: Na mesma linha de pensamento, avaliar as estratégias com sentido utilitarista prático tal como os livros de receita, a ser seguido na forma de uma prescrição docente acrítica, inflexível e copiosa. A solução do ensino está associada, numa lista de ingredientes, leia-se materiais e recursos, bem como do modo de preparo, que se encadeamento de etapas por etapas a serem seguidas à risca pelo professor.

3. Perda da totalidade pedagógica: a estratégia é vista de forma isolada dos componentes do ensino que determinam a prática docente, como a relação de interdependência entre método-objetivo-conteúdo, organização do planejamento escolar, sem a devida vinculação com a avaliação da aprendizagem no processo de seu desenvolvimento;

4. Lúdico pelo lúdico: considerada como uma saída para as ditas aulas expositivistas tradicionais e admitidas como prática pedagógica ultrapassada. O significado do ato de fazer "brincando", pode reduzir o sentido prático que o lúdico pode proporcionar, como o desenvolvimento de operações mentais criativas, prazerosas e dar significado ao conhecimento que se deseja ensinar. 
Ao mesmo tempo, elas não devem aparecer na sala de aula, apenas como alternativa para "rechear" as outras aulas de cunho expositivistas. Devem, acima de tudo, corresponder aos objetivos dos conteúdos que se deseja ensinar. As estratégias não podem ser vistas como uma lista de propostas de ensino mecânicas.

Relacionado ao trabalho do professor, o sucesso das estratégias encontra-se associada ao processo de ensino e da aprendizagem que ele realiza. Assim, a importância da mediação no entendimento de como se processa a relação entre os sujeitos envolvidos - aluno e professor - e conhecimento a ser mobilizado - saber. A mediação, no caso a pedagógica, configura-se na oportunidade que dois atores sociais, professor e aluno, são interpostos ao conhecimento novo ou a ser aprimorado. Conforme Dias (1995) explicita que:

Na psicologia cognitiva, designa-se por mediação "uma experiência refletida e instrutiva em que uma pessoa bem intencionada, experiente e ativa, geralmente um adulto, se interpõe entre o indivíduo e as fontes de estímulo. (Dias, 1995, p. 67 apud Vianin, 2013, p. 187).

É importante ressaltar que, a categoria da mediação, está presente em várias tendências pedagógicas e teorias de ensino, não sendo uma dimensão exclusiva da abordagem vigotskiana. No entanto, a concepção de mediação aqui adotada, é influenciada por elementos que norteiam uma base teórico-conceitual socioconstrutivista.

Nesta perspectiva, Houssaye (1993) propõe dois modelos denominados de triângulo pedagógico, que busca analisar o papel do professor diante do aluno e do saber.

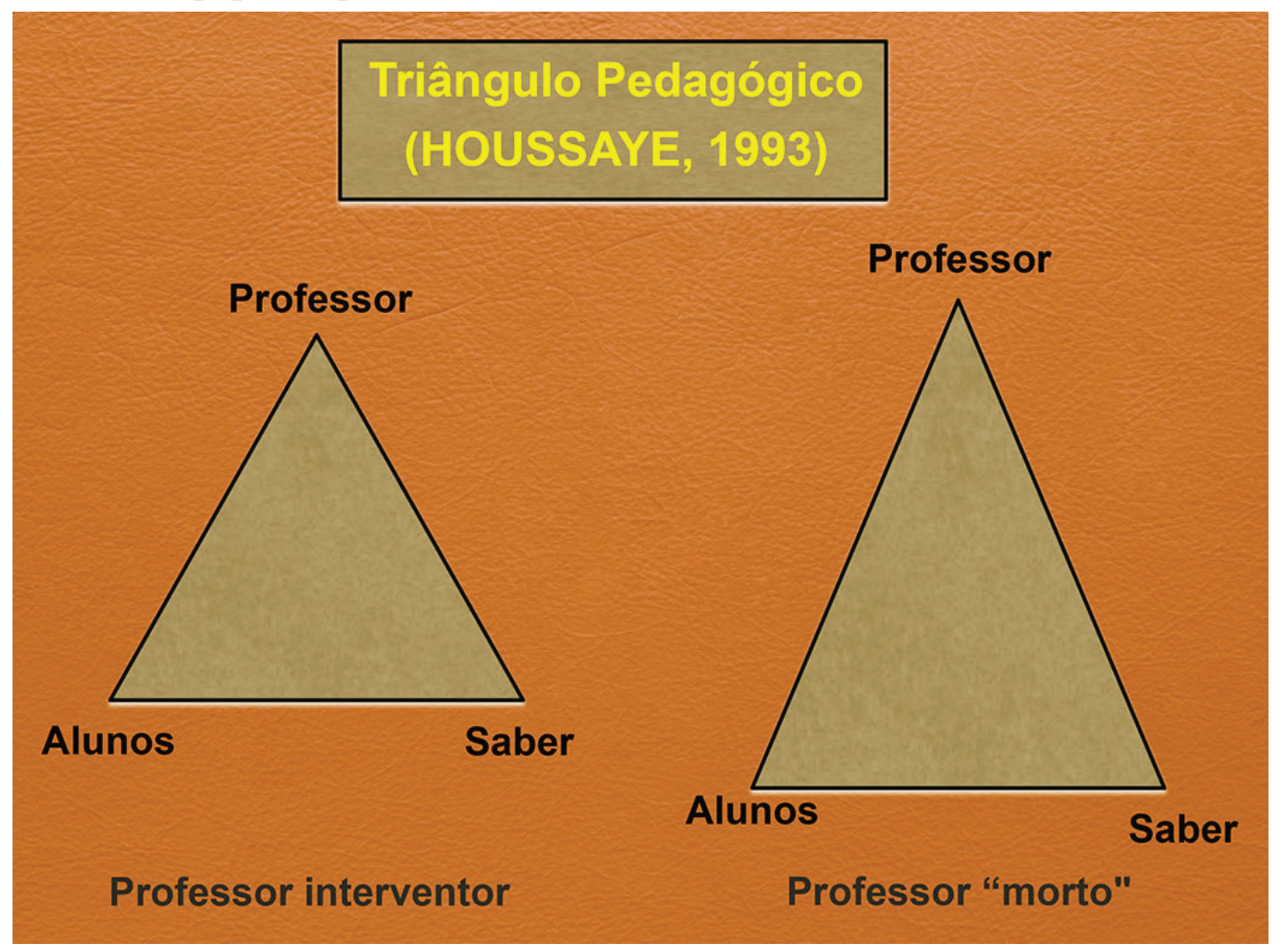

Figura 1: Triângulo Pedagógico.

Fonte: VIANIN, Pierre. In: Dificuldades de aprendizagem: estratégias de ajuda a alunos com dificuldades de aprendizagem. Porto Alegre: Penso, 2013, p. 189. 
Esse modelo composto por esses três elementos é interessante para analisarmos atividade do professor ora ação interventora direta da estratégia de ensino, ora numa situação de distanciamento, consciente e planejado, que não intervém direta, mas é um ato pensado, com o objetivos de desenvolver de forma autonôma certas operações mentais e competências, necessárias para amplicação e mobilização do conhecimento.

Nesta linha de pensamento, sem a presença do adulto, a criança aproveitaria menos os estímulos do seu ambiente. Quando a mediação didática encontra-se organizada num trabalho docente planejado, o ato da aprendizagem, mesmo a priori sendo realizada, sem necessáriamente ter a presença direta do professor, é um ato coordenado para desenvolver a autonomia do aluno. No entanto, "[...] No processo de ensinar, o professor mantém uma relação privilegiada com o saber, e situa-se no processo magistral da transmissão do saber." (189).

Esses elementos são fundamentais para compreender o desenvolvimento das operações mentais, o papel desempenhado pelo professor, bem como se desenvolvem as competências na perspectivas do zona proximal de aprendizagem e desenvolvimento.

\section{O ENSINO DOS CONTEÚDOS DO CLIMA NA GEOGRAFIA ESCOLAR}

Alguns estudos, dentre eles Maia (2010), Oliveira et al. (2012), Rossato e Silva (2007) e Oliveira (2011), têm apontado muitas dificuldades dos escolares na formação de conceitos científicos em climatologia, sendo estes reconhecidos desde as séries iniciais e a fase do $6^{\circ}$ e $7^{\circ}$ Ano do Ensino Fundamental, em que se deparam com uma grande carga de conteúdos de Geografia Física, com especial destaque para o clima.

Diante disso, destacamos a necessidade de se trabalhar a diferenciação de alguns conceitos introdutórios, como tempo e clima, elementos e fatores climáticos e previsão do tempo.

Segundo Rossato (2012) o objetivo do ensino dos conteúdos do clima no Ensino Fundamental perpassam no sentido de contribuir para a ampliação de noções de conceitos que envolvem tanto a climatologia, quanto a meteorologia, sujeitos a diferenciação entre tempo e clima; a importância dada ao estudo da meteorologia; o conhecimento que envolve os elementos que compõem o clima; o entendimento dos fatores geradores das estações do ano; assim como, o conhecimento regional da dinâmica climática que faz parte do território, cujo alunos habitam, no caso, o Rio Grande do Sul.

Mais do que conteúdo, o importante é como ensinar, no contexto da geografia, os conceitos referentes à compreensão da climatologia. Podemos ensinar a partir do conceito de lugar - como espaço próximo, espaço vivido e como espaço de expressão de relações horizontais (relações sociais mais amplas determinando em parte a especificidade dos lugares. Há necessidade da constante articulação da observação com a conceituação do fenômeno observado, tarefa que é feita por meio das mais diversas técnicas pedagógicas. (Rossato E Silva, 2007, p. 106).

Durante a realização das atividades práticas, os alunos "[...] estabeleceram relações entre variação do tempo meteorológico e dos hábitos da população. O ensino dos conteúdos do clima e dos fenômenos meteorológicos, podem ser realizados por meio da interpretação da dinâmica atmosférica, no sentido da dedução de hipóteses que "[...] evidenciassem as relações entre os diferentes elementos do clima." (Rossato, 2012, p. 130). Conforme podemos verificar na citação abaixo: 
Com o estudo, identifica-se que a proposta de compreensão dos conceitos a partir de experiências e/ou eventos cotidianos é mais eficaz. Disto, conclui-se que o entendimento de clima pressupõe o entendimento do conceito de tempo meteorológico estar cotidianamente inserido na vida das pessoas, sendo entendido como as condições momentâneas do ar atmosférico em um determinado lugar. (RoSsato, 2012, p. 132).

Alguns conceitos, apresentam nível de dificuldade aprendizagem por parte dos alunos, tais como pressão atmosférica e umidade relativa do ar, por demandarem um elevado nível de abstração. Segundo Maia (2010):

A atual realidade escolar no Brasil demonstra que o ensino de climatologia não tem sido desenvolvido no ensino fundamental II, ou, quando ocorre, é ministrado baseado na climatologia tradicional e separativa, cujos fatores elementos do clima são analisados individualmente, retratando-se a natureza de forma estática e totalmente destituída do real. (p. 22).

Nessa perspectiva, Oliveira et al. (2012) afirmam que os desafios para ensinar os conteúdos do clima nas escolas estão relacionados a formação inicial dos professores, bem como a falta de conhecimentos básicos da climatologia. Para fins de identificação, podemos chamar esses conteúdos temáticos aqui de uma espécie de "alfabetização climato-meteorológica", ou seja, que dão suporte no entendimento dos conceitos, processos e fenômenos trabalhados na sala de aula. Segundo Oliveira et al. (2012):

O professor de geografia no ensino fundamental II enfrenta dificuldades em ensinar Climatologia, em decorrência da falta de conhecimento prévio dos alunos, referente aos temas trabalhados e dos professores, algo que pode ser explicado pela má formação acadêmica, ou na própria negligência desses profissionais. (p. 49)

É importante ressaltar que, a abordagem da climatologia adotada nesta pesquisa baseia-se na concepção de Monteiro (1999), em que analisa o clima como sistema aberto, singular, altamente complexo evolutivo e auto regulável, sintetizada na tríade Sistema Clima Urbano (SCU).

\section{A ELABORAÇÃO DE MATERIAIS DIDÁTICOS ENQUANTO ESTRATÉGIAS DE ENSINO PARA CONTEÚDOS DO CLIMA NA GEOGRAFIA ESCOLAR}

A investigação em apreço, trata-se de uma pesquisa qualitativa em educação, com várias técnicas empregadas, entre elas destacam-se a pesquisa colaborativa, o grupo focal, a pesquisa participativa e a pesquisa-ação. Está consubstanciada na investigação dos elementos e fenômenos do clima urbano na Região Metropolitana de Goiânia - RMG - e sua utilização no ensino de o Ensino de Geografia, com conteúdos específicos de climatologia por meio da produção e utilização de materiais didáticos.

A proposta desta pesquisa se fundamenta na elaboração de material didático sobre a Região Metropolita de Goiânia, que se desenvolve no LEPEG na UFG. Esta investigação se realizou entre os anos de 2011 e 2013, onde foram identificados a escassez de materiais didáticos temáticos que versam sobre a realidade local.

Um aspecto relevante desta pesquisa, é a proposta de aglutinar professores da rede de ensino público junto ao grupo de pesquisadores da universidade. A equipe de pesquisadores é formada por professores universitários da Universidade Federal de Goiás - UFG e Universidade Estadual de 
Goiás - UEG; alunos de graduação pós-graduação do curso de Geografia da UFG, técnica em meteorologia e professores de geografia da Rede de Ensino Estadual de Goiás e Municipal de Goiânia.

Objetiva-se a elaboração de materiais didáticos, bem como a realização de cursos de formação continuada de professores de Geografia. Como produtos desta pesquisa está em fase de desenvolvimento o fascículo intitulado "Dinâmicas Climáticas"2, o Manual de Oficinas dos conteúdos do clima, e a elaboração do site que agregará elementos contidos nos dois materiais anteriores supracitados, bem como dados e informações que possibilitem tanto o professor, como os escolares realizarem pesquisas.

Partimos das seguintes problemáticas para realização desta pesquisa: a primeira refere-se a escassez de materiais didáticos para o ensino de Geografia voltados para análise de conteúdos específicos do local de vivência dos alunos, ou seja, na RMG; o segundo aspecto está relacionado às dificuldades que professores tem em ensinar e os alunos tem em aprenderem os conteúdos de geografia física; e, em terceiro lugar, o significado da temática do clima na sociedade para interpretação da realidade, colaborando para elaboração de um olhar geográfico atento para as dinâmicas climáticas do meio urbano.

Os procedimentos metodológicos estão consubstanciados nas seguintes etapas:

- Criação do grupo de pesquisadores da REPEC e organização do grupo focal;

- Leituras, discusão e análise de materiais bibliográficos disponíveis: são discutidos e apresentados as diretrizes da elaboração dos materiais didáticos iniciales del material bibliográfico disponible: orientaciones para la elaboración del material;

- Produção e confecção do fascículo, manual de oficinas e site: todas propostas metodológicas dirigem-se para escolares na fase do Ensino Fundamental II, mas são os profesores, através das oficinas de avaliação, que apontam as adequações necessárias para melhorar a qualidade do material.

Podemos visualizar a proposta metodológica desta proposta na figura 2:

\section{Proposta Metodológica}

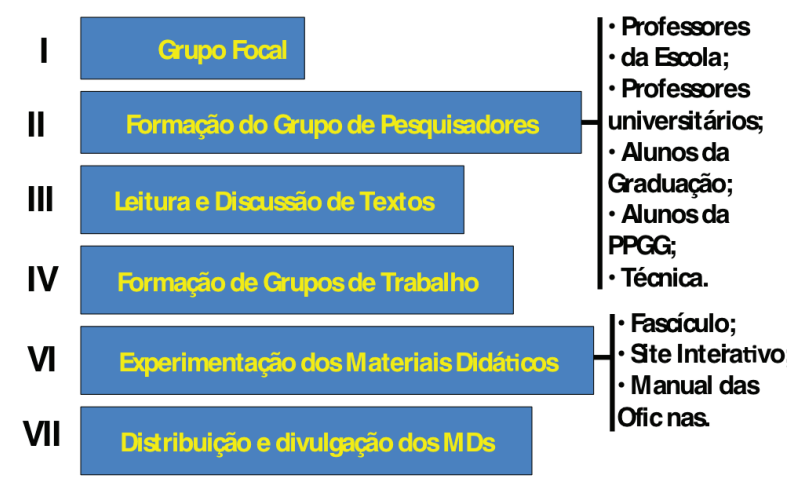

Figura 2: Proposta Metodológica da pesquisa. Org.: Alves, A. O. 2013.

2 O projeto foi aprovado e financiado junto à Fundação de Âmparo à Pesquisa do Estado de Goiás - FAPEG, no período de 2011-2013, sob o título "Elementos e fenômenos do clima urbano na Região Metropolitana de Goiânia - GO e sua utilização no Ensino de Climatologia". 
Encontra-se em fase de desenvolvimento três canais de produção de materiais didáticos e estratégias metodológicas para o Ensino de Climatologia, a saber: a) Elaboração textual dos capítulos do fascículo; b) Planejamento e concepção de site interativo em climatologia geográfica; c) Finalização do Manual de Oficina com experiências didático-pedagógicas.

A sequencia didática do fascículo está consubstanciada em cinco partes: Conversa Comigo, Traços e retratos, Aprofundando o tema, O que foi que aprendi mesmo? e Conectando com a Realidade. Cada um deles possui uma função:

Parte 1 - Conversa Comigo: busca problematizar e incentivar os alunos a pensar sobre o tema. É o cotato inicial com o conteúdo "novo";

Parte 2 - Traços e retratos: são apresentadas as representações cartográficas, dados, informaç̧ões e ilustracões dos municipios que compõem a RMG;

Parte 3 - Aprofundando o tema: sistematização e maior detalhamento dos conteúdos. Neste item são ampliandas e aprofundadas as temáticas.

Parte 4 - O que foi que aprendi mesmo?: apresenta uma síntese dos conteúdos abordados;

Parte 5 - Conectando com a Realidade: relaciona os conteúdos estudados com a realidade, além de indicar outras fontes de pesquisa.

O fascículo é composto por quatro capítulos com as seções supracitadas. A organização desta permite que os capítulos sejam trabalhados sem sequência de ordem, uma vez que as temáticas propostas são independentes. Além disso, podem ser abordados para escolares do Ensino Médio, mesmo tendo uma linguagem mais adequada para a segunda fase do Ensino Fundamental. A estrutura dos capítulos do fascículo ficou da seguinte forma:

Capítulo 1 - Entendendo o conceito de clima;

Capítulo 2 - Ai que calor! Entendo o conforto térmico;

Capítulo 3 - O impacto hidrometeórico;

Capítulo 4 - O ar que eu respiro! Qualidade do ar.

O capítulo 1, intitulado "Entendendo o conceito de clima" traz a partir da concepção do Sistema Clima Urbano (SCU), baseado na concepção de Monteiro (1976), a diferenciação de tempo e clima e aponta e introduz elementos da denominada alfabetização climato-geográfica. Vejamos algumas enunciados da teoria e ação operativa das pesquisas sob esta perspectiva:

1. Denomina-se como um sistema singular, que abrange num dado espaço terrestre, a combinação do clima local (fato natural) e a cidade (fato social); [...] 2. Espaço urbanizado mantém íntimas relações com o ambiente regional em que se insere; 3. SCU funciona como sistema aberto; 4. As entradas de energia do SCU são de natureza térmica: oriundas da fonte primária de energia de toda a Terra - o Sol; 4. A estrutura interna do SCU não pode ser definida pela simples adição de suas partes, mas pela conexão entre elas; 5 . SCU se modifica, conforme se reestrutura as condições de 
urbanização internas da cidade; 6. SCU é passível de auto-regulação, na medida que conhece seu funcionamento e suas "disfunções", pode nele intervir, como medidas de planejamento. 7. Canais de percepção humana, derivados da aglutinação no complexo energético de elementos termodinâmicos, físico-químicos e hídricos.

Dentro da perspectiva do SCU, nos apropriamos da proposta dos canais de percepção humana, que se baseia na seguinte análise:

a. Conforto térmico: são os componentes termodinâmicos (calor, ventilação e umidade) em suas relações.

b. Qualidade do ar: engloba tanto a poluição do ar c em combinação às outras formas de poluição (água, solo, etc).

c. Meteroros de Impactos: todas as formas meteóricas, hídricas, mecânicas e elétricas, que são capazes de causar alterações significativas no meio urbano.

A previsão do tempo constitui importante conhecimento para a sociedade, seja essas vinculadas ao setor econômico ou àquelas relacionadas ao planejamento das atividades dos indivíduos que habitam tanto no campo, como na cidade. Sendo um conteúdo de grande contribuição, as informações de previsão do tempo são veiculadas em vários canais de informação, como na mídia impressa (jornais), televisiva (programas e "revistas" informativas) ou virtual (nos sites de previsão de tempo).

Para tanto, é necessário que o professor de Geografia apresente o significado destes conteúdos na formação dos escolares. A leitura dos quadros de previsão do tempo é composto por uma linguagem textual e por signos, conforme podemos verificar na figura 3:

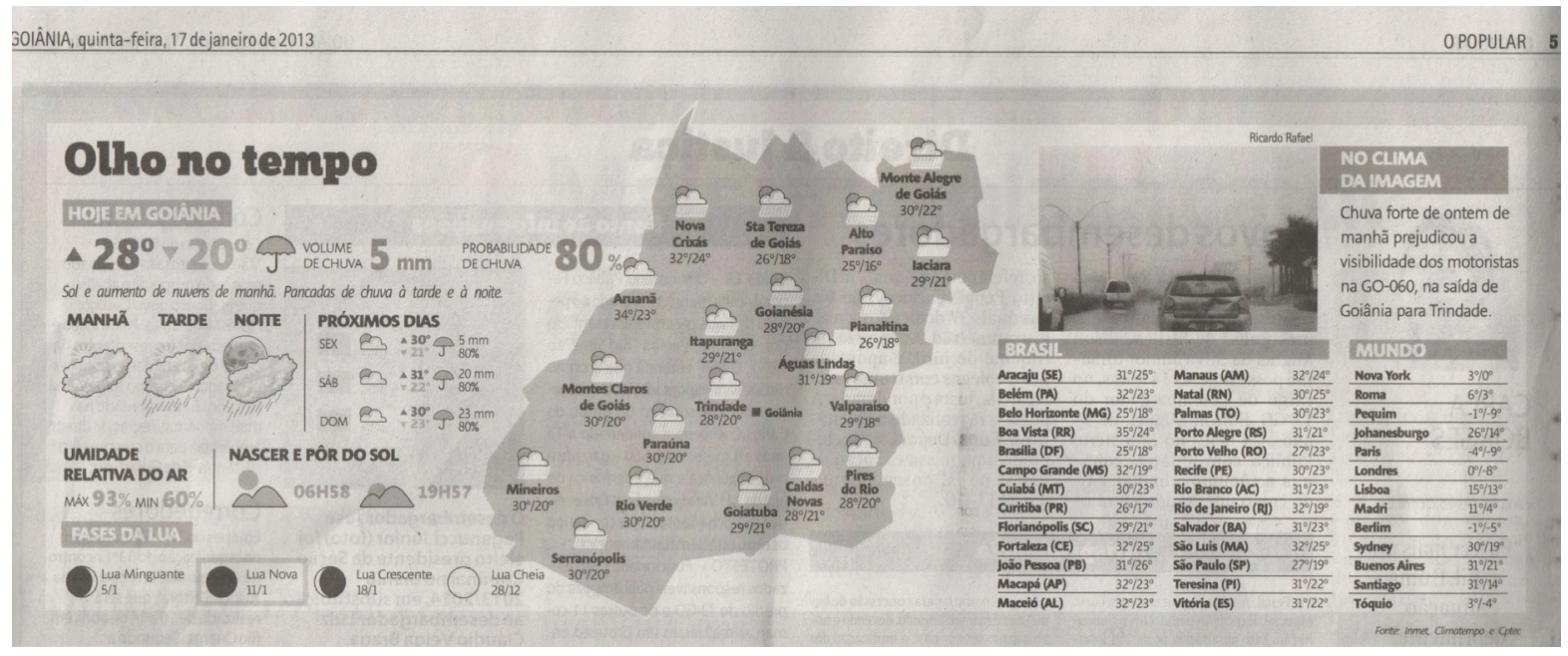

Figura 3: Previsão do Tempo no Estado de Goiás - Brasil.

Fonte: Jornal O Popular, 11/06/12.

Conforme podemos notar, o quadro apresenta um conjunto de informações necessárias para interpretação da previsão do tempo, como a distribuição de signos de previsão do tempo no mapa do estado de Goiás, as temperaturas mínimas e máximas, o detalhamento de elementos climáticos (temperatura, umidade e precipitação) para a cidade de Goiânia durante o dia, como também a previsão para os dias posteriores. 
Essas informações são importantíssimas para a identificação dos conteúdos meteorológicos e climáticos, com vistas à elaboração de um olhar geográfico de forma a contribuir no processo de interpretação da relação sociedade natureza. Rossato e Silva (2007) expõem a importância do cotidiano do tempo meteorológico com vistas à compreensão de conceitos climatológicos. Tendo como ponto de partida o estudo do espaço geográfico, "[...] o aluno refletirá sobre a análise da dinâmica social, da dinâmica da natureza e da interrelação delas. [...]” (p. 104).

Nessa mesma linha de pensamento, se faz necessário a realização de estratégias de ensino que promova a alfabetização espacial. Callai (2005) aponta que o processo de alfabetização espacial promove a leitura do mundo, este é acompanhado, anteriormente, por meio da leitura da palavra:

Como realizar a leitura da palavra por meio da leitura do mundo? E como fazer a leitura do mundo por meio da leitura da palavra? Esse pode ser o desafio para pensar um aprendizado da alfabetização que seja significativo. Partindo do fato de que a gente lê o mundo muito antes de ler a palavra, a principal questão é exercitar a prática de fazer a leitura do mundo. E pode-se dizer que isso nasce com a criança. (p. 232).

Deste modo, a construção a leitura da palavra, pode intensificar ainda mais a leitura do mundo, contribuindo para a leitura dos signos e significados dos conceitos ligados a climatologia e meteorologia. Cabe à nós educadores desenvolver atividades que promovam a leitura dos símbolos da previsão do tempo, contribuindo para a interpretação da organização do espaço e apropriação do uso e ocupação do solo que dele se faz.

Sobre a relação entre o conteúdo conceitual e procedimental, afirmam a necessidade de interação entre o sujeito (professor) e objeto (conteúdo selecionado). Dessa forma, Rossato e Silva (2007) ressaltam a relação entre "O que ensinar?" e "Como ensinar", anteriormente apresentado por Suertegaray (2010):

Mais do que o conteúdo, o importante é como ensinar, no contexto da geografia, os conceitos referentes à compreensão da climatologia. [...] Há a necessidade da constante articulação da observação com a conceituação do fenômeno observado, tarefa que é feita por meio das mais diversas técnicas pedagógicas. (p. 106)

No fascículo de dinâmicas climáticas é apresentado um quadro demonstrativo que tenta suprir esta demanda, recorrente na leitura das previsões de tempo e ausente nos conteúdos dos livros didáticos de Geografia. Conforme podemos verificar, são apontados alguns exemplos de ícones necessários para interpretação do tempo apresentados nas linguagens meteorológicas: 


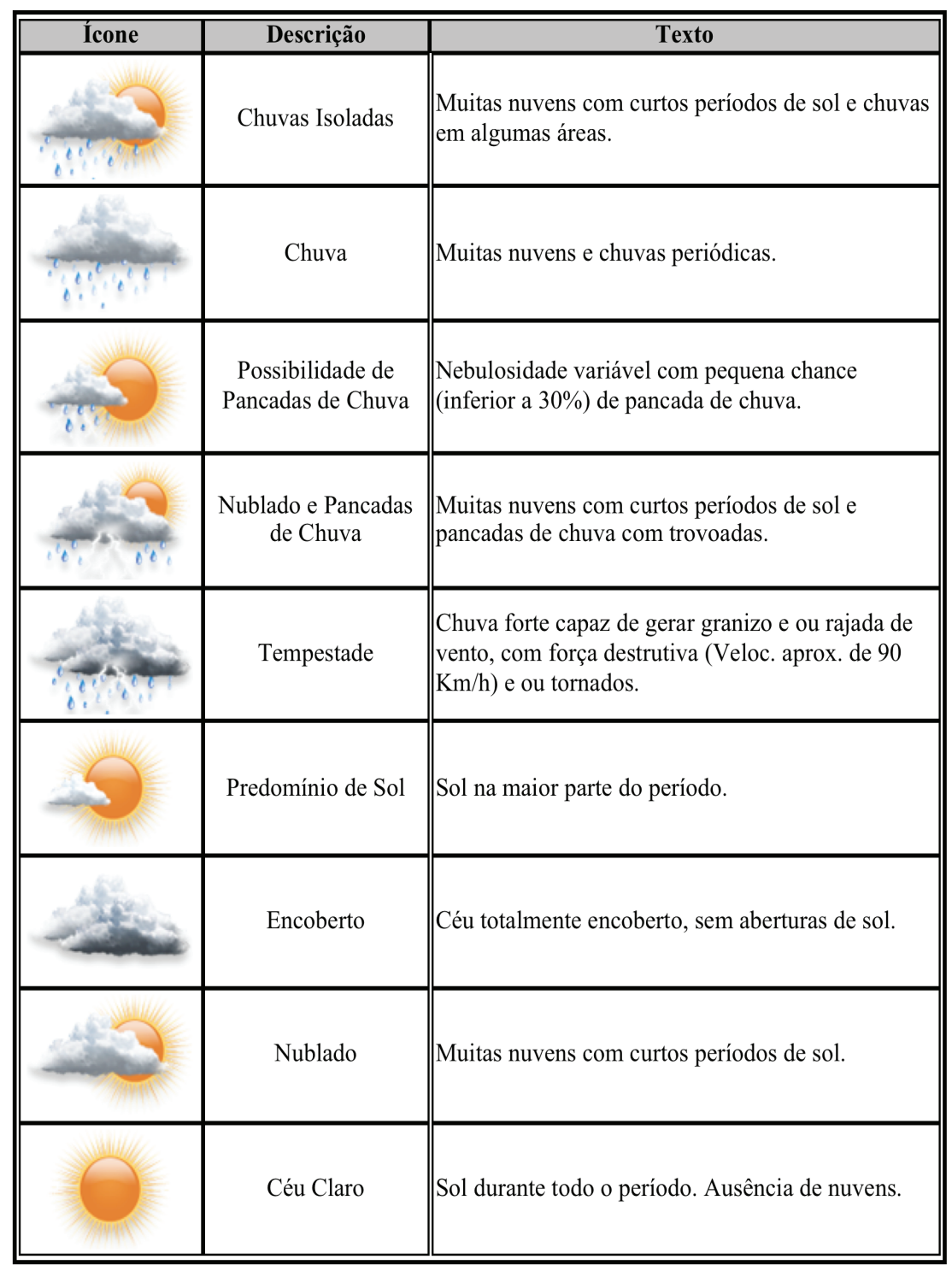

Figura 4: Quadro dos signos do tempo meterorológico. Org.: Alves, A. O. Barros, J. R.Dinâmicas Climáticas. Goiânia: Gráfica América, 2013. (no prelo)

Conforme podemos notar, o quadro apresenta três itens principais, a saber: o signo da previsão do tempo, que possui como variantes de representação, o sol, as nuvens e a precipitação; a descrição do significado do signo e um exemplo mais detalhado da previsão do tempo, com informações e a interpretação textual do conteúdo meteorológico.

Esperamos que a utilização desse quadro - presente no fascículo de Dinâmicas Climática possa contribuir para a interpretação da informação meteorológica, e assim promover a alfabetização geográfica no sentido de contribuir para o ensino e aprendizagem da leitura de mundo - apresentado por Callai (2005) e autonomia dos escolares na sua vida cotidiana.

Nos capítulos subsequentes, a opção teórico-metodológica, está consubstanciada na organização de temáticas nos chamados canais de percepção proposto por Monteiro (1976). São canais de percepção humana, os indicadores dos problemas e valores dos fatos geográficos que são assumidos 
no clima da cidade:

a) Conforto térmico - Englobando as componentes termodinâmicas que, em suas relações, se expressão através do calor, ventilação e umidade nos referenciais básicos a esta noção. É um filtro perceptivo bastante significativo, pois afeta a todos permanentemente. Constitui, seja na climatologia médica, seja na tecnologia habitacional, assunto de investigação de importância crescente.

b) Qualidade do ar - A poluição é um dos males do século, e talvez aquele que, por seus efeitos mais dramáticos, atraia mais a atenção. Associda às outras formas de poluição (água, solo, etc.) a do ar é uma das mais decisivas na qualidade ambiente urbana.

c) Meteoros de impactos - aqui estão agrupadas todas aquelas formas meteóricas, hídricas (chuva, neve, nevoeiros) mecânicas (tornados) e elétricas (tempestade), que assumindo, eventualmente, manisfestações de intensidade são capazes de causar impacto na vida da cidade, pertubandoa ou desorganizando-lhe a circulação e os serviços. (MONTEIRO e MENDONÇA, 2011, p. 24)

Nesse sentido, a organização dos capítulos atende a prerrogativa dos impactos ambientais que afligem a dinâmica do clima urbano na cidade, tendo como destaque a problematização dos fenômenos meteorológicos. Para tanto, destacam-se nesse trabalho, a sequência dos seguintes capítulos:

No capítulo 2, intitulado "Ai que calor! Entendo o conforto térmico", o objetivo é apresentar as relações que envolvem a alteração da temperatura, ventilação e umidade, tendo como principal referência de análise, o fenômeno das Ilhas de Calor;

O Capítulo 3, intitulado "O impacto hidrometeórico", pressupõem analisar um dos elementos do canal de percepção denominado "meteroros de impactos", tendo como destaque a dinâmica natureza com o aparecimento da chuva no ambiente urbano fortemente alterado.

O Capítulo 4, intitulado "O ar que eu respiro! A qualidade do ar" procura apresentar exemplos dos efeitos da poluição atmosférica acometidos no meio urbano, juntamente com processos climáticos como o fenômeno da inversão térmica e chamado smoke.

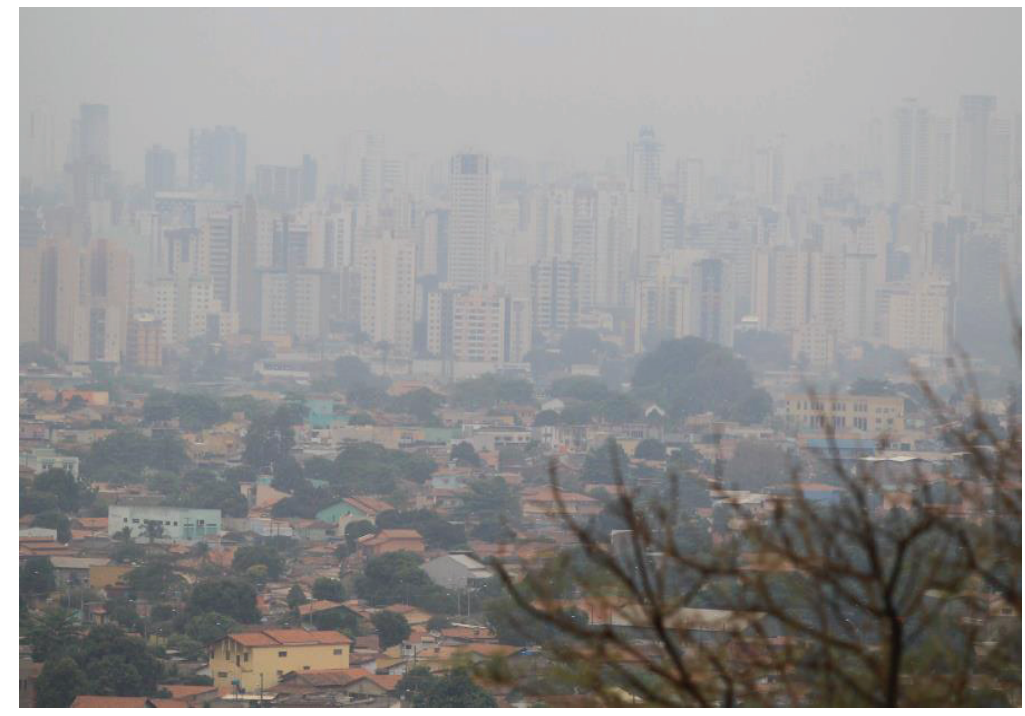

Figura 5: Céu acinzentado resultado de inversão térmica e da poluição atmosférica em GoiâniaGO. Fonte: O Popular, 18 setembro de 2012. 
O ponto de partida está na construção dos conceitos científicos à partir da construção dos conceitos cotidianos voltados para a Geografia Escolar. O estudo sobre o conceito ocupa um destaque muito grande para Vigotski (2000) em seu livro "A construção do pensamento e da linguagem".

O conceito é uma forma de explicação do pensamento, um sistema de formulação. A criança tem uma grande capacidade de intuir, fazer inferências sobre a compreensão da dinâmica da natureza, dado o caráter de observação dos elementos do meio físico que a mesma possui. Nessa fase, a criança possui a criança tem a possibilidade de construir o conceito cotidiano.

O conceito cotidiano é um conceito empírico, que pode carregar explicações espontâneas, aproximações científica, pode ser culturalmente instituído, como por exemplo através religião. Nesse caso, à título da complexidade do conceito cotidiano, ele possui domínio conceitual analítico e experimental, em contraposição ao conceito espontâneo, dada a sua complexidade.

Nessa perspectiva, estudos sobre o ensino do clima tem apontado como alternativa, a utilização do saberes popular como alternativa para facilitar o ensino e aprendizagem do tempo e clima. Maia (2010) aponta que o saber popular na forma dos ditos populares cumpre função fundamental na construção dos conceitos:

Pelo breve histórico dos adágios populares relacionados à previsão do tempo e clima, e até mesmo considerando circunstâncias de maior «evolução civilizatória", vê-se que os conhecimentos a ela correlatos são fruto de observação empírica e repassada de geração para geração. Muitas das vezes são comprovados cientificamente, mas também podem ser apenas crendices que vão sendo propagadas de gerações em gerações. (p. 3)

Nessa mesma perspectiva, procuramos apresentar no Capítulo 3, que trata dos impactos hidrometeóricos, um exemplo do saber popular propagado na RMG, e quiça no Estado de Goiás, bem como em outras regiões do Centro Oeste e Sudeste, , denominada de "enchente de São José", caracterizada por uma chuva de grande intensidade que marca o final da estação quente e chuvosa - o verão.

Para tanto, foi elaborado um quadro intitulado "As águas de março", onde é apresentado o relato de um citadino (autor desconhecido) sobre a enchente de São José, e do outro, a análise de um especialista da área, cuja explicação aponta porque chuvas de grande intensidade marcam o fim da estação do verão. Observe a Figura 00, intitulado As águas de março - entre o dito popular e as explicações científica": 


\section{AS ÁGUAS DE MARÇO}

\section{ENTRE O DITO POPULAR E AS EXPL ICAÇÕES CIENT ÍI FICAS}

\section{Aenchente deSãoJosé}

Autor Desconhecido Amanhã vai chover o dia inteiro, poisé dia de São José; Vai cair chuva forte, vai ter alagamento, córregos vão transbordar;

Amanhã vai chover o dia inteiro, poisé dia de São José; As ruas ficarão alagadas, bueiros vão entupir, carros vão rodopiar;

Amanhã vai chover o dia inteiro, poisé dia de São José; Vai ter muitos aguaceiros, pesscas serão arrastadase doenças vão se proliferar;

Amanhã vai chover o dia inteiro, poisé dia de São José; Vai ter deslizamentos, casas serão invadidas pelas águas e os telhados vão voar;

Se amanhãé diade São José,

Contra a enchenteeu nada posso fazer?

\section{Chuvas sãocomunsnessaépoca}

do ano

Por Diego Tarley

As chuvas torrenciais, que geralmente trazem uma série de transtornos nas cidades (como enchentes), são resultado das elevadas temperaturas que são verificadas ao longo dos dias mais quentes. Essas chuvas devem ser entendidas como consequência do planeta estar numa posição mais inclinada ao Sol neste período do ano, e, por isso, receber mais diretamente a energia solar - que justificam as maiores temperaturas durante o verão, a estação mais quente do ano. Esse maior aquecimento provoca a ascensão do ar durante o dia (o ar mais quente tende a subir), e ocasiona uma corrente ascendente de ar para a atmosfera, que ao encontrar um ar mais frio (sabendo que na medida que subimos a temperatura tende a diminuir), ele resfria, encontra certa umidade e precipita na forma de chuvas no final da tarde ou início da noite. Desta forma, a enchente pode vir acompanhada da última grande chuva da estação das águas, que são comuns na segunda quinzena do mês de março.

Figura 6: Explicação da enchente de São José por meio do saber popular e científico. Org.: Alves, A. O. Barros, J. R. Dinâmicas Climáticas. Goiânia: Gráfica América, 2013. (no prelo)

A utilização desse tipo de linguagem permite instigar nos escolares o interesse em aprender o conteúdo do clima, uma vez que os mesmos demonstram grande dificuldade de compreensão e assimilação, ou seja, esse conteúdo geográfico se apresenta como interessante, mais de difícil de compreensão. Ao mesmo tempo, o professor, por meio da sua ação docente, desempenha papel fundamental ao confrontar os conhecimentos do saber popular com os científicos acerca dos conceitos que envolvem os conteúdos do clima na Geografia Escolar.

\section{CONCLUSÃO}

Apresentamos neste ensaio, o potencial teórico-metodológico do material didático - fascículo - enquanto estratégias de ensino voltados para o ensino dos conteúdos do clima para a Geografia Escolar.

Esse potencial se faz em virtude da mediação didática realizada pelo professor, que busca mobilizar conceitos da dinâmica do meio urbano através da construção de conceitos cotidianos e científicos.

As estratégias de ensino devem ser bem planejadas, sem desvalorizar a discussão sobre os objetivos os conteúdos no qual a técnica será aplicada.

Deve-se pensar no processo de construção do conhecimento que se desenvolve por várias operações mentais portanto, as estratégias devem mobilizar o desenvolvimento da capacidade de apren- 
dizagem, nesse sentido o material didático, possui um potencial teórico e prático para realização dessas atividades.

O trabalho em apreço tem demonstrado a importância de fortalecer pesquisas colaborativas com participação de grupo heterogêneo de professores-pesquisadores. Na primeira etapa da investigação, o grupo de pesquisadores debateu vários textos relacionados ao clima urbano, leituras de teses e dissertações, livros didáticos e paradidáticos com experiência didático-pedagógicas em climatologia e meteorologia, análise do conteúdo de climatologia em livros didáticos de Geografia de $5^{\circ}$ e $6^{\circ}$ Ano do Ensino Fundamental (aprovados pelo PNLD e mais utilizados na RMG), levantamento de sites e CDs com conteúdo climático geográfico para consultas escolares.

É importante ressaltar que, a abordagem utilizada busca mobilizar conceitos da dinâmica do clima urbano, iniciando coma a diferença entre tempo e clima; a classificação de elementos, fatores e fenômenos climáticos; entre eles destacam-se os processos de inversão térmica, smoke, impacto hidrometeórico e ilhas de calor.

\section{REFERÊNCIAS}

Anastasiou, L. D. G. C. Alves, L. P. (Orgs.) Processos De Ensinagem Na Universidade: Pressupostos Para Estratégias De Trabalho Em Aula. $3^{\circ}$ Ed. Joinville: Univille, 2004.

Callai, H. C. Aprendendo A Ler O Mundo: A Geografia Nos Anos Iniciais Do Ensino Fundamental. Cad. Cedes, Campinas, Vol. 25, Nº6, P. 227-247, Maio/Ago. 2005. Disponível Em: Disponível Em Http://Www.cedes.unicamp.br.

Cavalcanti, L. Geografia E Práticas De Ensino. Goiânia: Alternativa, 2002.

Cavalcanti, L. O Ensino De Geografia Na Escola. Campinas: Papirus, 2012.

Demo, P. Educar Pela Pesquisa. Campinas: Autores Associados, 2005.

Farias, I. M. S. De. [Et Al.] DidÁtica E Docência: Aprendendo A ProfissãO. Brasília: Liber Livros, 2009.

Libâneo, J. C. DidÁTica. São Paulo: Cortez, 1994.

Luckesi, C. C. Filosofia Da Educação. São Paulo: Cortez, 1991.

Maia, D. C. A Utilização Dos Ditos Populares E A Observação Do Tempo E Do Clima. Revista Geografia: 2010. Disponível Em: <Http://Geografia.uol.com.br/Geografia/Mapas-Demografia/34/Artigo194428-1.Asp> Acesso Em: 20/10/2013.

Massetto, M. T. CompetÊncia Pedagógica Do Professor Universitário. São Paulo: Summus, 2003.

Monteiro, C. A. De F. MendonçA, F. Clima Urbano. $2^{\circ}$ Ed. Contexto: São Paulo, 2011. 
Monteiro, C. A. De F. Teoria E Clima Urbano. São Paulo: Igeo/Usp, 1976.

Oliveira, D. J. L. De. Os Desafios De Ensinar A Climatologia Nas Escolas. In: Ii Congresso De Educação - Ueg/Unu - Unidade De Iporá - A Formação De Professores: Uma Proposta De Pesquisa A Partir Da Reflexão Sobre A Prática Docente, 2012, P. 47-51.

Perrenoud, P. Construir Competências Desde A Escola. Porto Alegre: Artmed, 1999.

Rangel, M. MÉtodos De Ensino Para A Aprendizagem E A Dinamização Das Aulas. $6^{\circ}$ Ed. Campinas: Papirus, 2005.

Rossato, M. S. Silva, D. L. M. Da Cotidianidade Do Tempo Meteorológico À CompreensÃo De Conceitos ClimatolóGicos. In: Rego, Nelson; Castrogiovanni, Antonio Carlos; Kaercher, Nestor (Orgs.) Geografia: Práticas Pedagógicas Para O Ensino Médio, 2007.

Rossato, M. S. Vivendo A Meteorologia Para Construir A Climatologia: Experiências PrÁticas No Ensino Fundamental. In: Cadernos De AplicaçãO. Porto Alegre: Ufrgs, Vol. 22, N 1, 2009, P. 113-144.

Sacristan, J. G. Consciência E Ação Sobre A PráTica Como LibertaÇão ProfissionAl De Professores. In: NóVoa, Antonio. Profissão Professor. Lisboa: Porto Editora, 1995.

Saviani, D. Escola E Democracia: Teorias Da Educação, Curvatura Da Vara, Onze Teses Sobre Educação E Política. $7^{\circ}$ Ed. São Paulo: Cortez, 1985.

Steinke, E. T. Climatologia Fácil. São Paulo: Oficinas De Textos, (2012).

Veiga, I. P. A. TÉcnicas De Ensino: Novos Tempos, Novas ConfiguraçõEs. Campinas: Papirus, 2006.

Veiga, I. P. A. TÉcnicas De Ensino: Por Que NãO? Campinas: Papirus, 1998.

Vianin, P. Dificuldades De Aprendizagem: Estratégias De Ajuda A Alunos Com Dificuldades De Aprendizagem. Porto Alegre: Penso, 2013, P. 189.

Vygotsky, L. S. A ConstruÇão Do Pensamento E Da Linguagem. Tradução: Paulo Bezerra. São Paulo: Martins Fontes (2009).

Zabala, A. A PrÁtica Educativa: Como Ensinar. Porto Alegre: Artmed, 2010. 